\title{
Operant matching is not a logical consequence of maximizing reinforcement rate
}

\author{
GENE M. HEYMAN and R. DUNCAN LUCE \\ Department of Psychology and Social Relations, Harvard University, Cambridge, Massachusetts 02138
}

\begin{abstract}
The distribution of behavior between concurrently available schedules of reinforcement approximates the distribution of reinforcements between the schedules. This equality, called matching, has been explained as an instance of the principle that organisms maximize reinforcement rate. However, a precise account of the relationship between the distribution of behaviof and reinforcement rate on the standard concurrent schedule shows that matching and maximizing are different.
\end{abstract}

The orderly data of behavior under concurrent schedules of reinforcement provide an opportunity to test some of our assumptions about choice and the economics of behavior. One basic finding is that the proportion of choices at each reinforcement source approximates the proportion of reinforcements earned there (Herrnstein, 1970). Every species tested matches behavior proportions to reinforcement proportions (de Villiers, 1977), and this simple symmetry has been found in free-ranging creatures as well (Baum, 1974). At a theoretical level, however, no consensus exists as to why organisms match (de Villiers, 1977). According to a recent account (Rachlin, Green, Kagel, \& Batallio, 1976), organisms maximize the sum of the reinforcement rates from the competing sources and this leads to matching. Rachlin et al. (1976) explicitly adopted a microeconomic framework, but their theory is implicit in recent definitions of reinforcement (Baum, 1973a), and it is consistent with current optimizing theories in ecology (Rapport \& Turner, 1977). Our purpose here is to give a precise account of the relationship between maximizing the overall reinforcement rate and matching in one situation often used to study choice in operant psychology, namely the concurrent variable-interval variable-interval schedule (conc VI VI). The result is that maximizing does not in general explain matching.

On a conc VI VI schedule, reinforcements are made available by two independent timers. Each is associated with a manipulandum for responses, and

This work was supported by Grant MH-15494 from NIMH to Harvard University. We are grateful to Richard Herrnstein for helpful comments and criticism. Reprint requests should be sent to: Gene M. Heyman, Andrus Gerontology Center, University Park, University of Southern California, Los Angeles, California 90007.

A comment on this paper and a reply appear in the Notes and Comment section of this issue.

-Editor's note. the distribution of programmed interreinforcement intervals is usually exponential (Fleshler \& Hoffman, 1962). When an interval is completed at a timer, a reinforcement is set up and the next response at that manipulandum is reinforced. For example, in a twolever box, a rat's first press at the "correct" lever following the setup is reinforced. The reinforced response resets that timer with a new random interval, and the process repeats itself. Because the two timers run independently, reinforcement may be available at any instant at neither, either, or both of the alternatives; and, for the same reason, the longer the subject remains at one alternative, the more likely it is that a reinforcer is available at the other one.

\section{A Model for Independent Conc VI VI Performance}

We derive an equation for the expected reinforcement rate for a conc VI VI schedule from three assumptions. The first is that the experiment uses a conc VI VI schedule with exponential distributions of intervals. This schedule is characterized by the two mean intervals, $V_{1}$ and $V_{2}$.

Next we must specify something about the subject's pattern of switching from one manipulandum to the other. Several studies, as well as data we present below, show that switching is well described as independent, exponential, interchangeover times with different means on the two sides. This means that the conditional probability of a switch from an alternative at time $t$ since the last switch is independent of t. Supporting evidence includes the following. Figures 1 and 2 (Heyman, 1979) present for pigeons estimates of the conditional probability of switching from one alternative to the other in a conc VI VI procedure in which reinforcement proportions were fixed (Stubbs \& Pliskoff, 1969-this procedure is described in more detail below). On the abscissa is the number of responses since the last switch, run length. A chi-square test established that the changeover probabilities in general do not differ from the 
VI $33.3 \mathrm{sec}$ and VI $300 \mathrm{sec}$ SCHEDULES

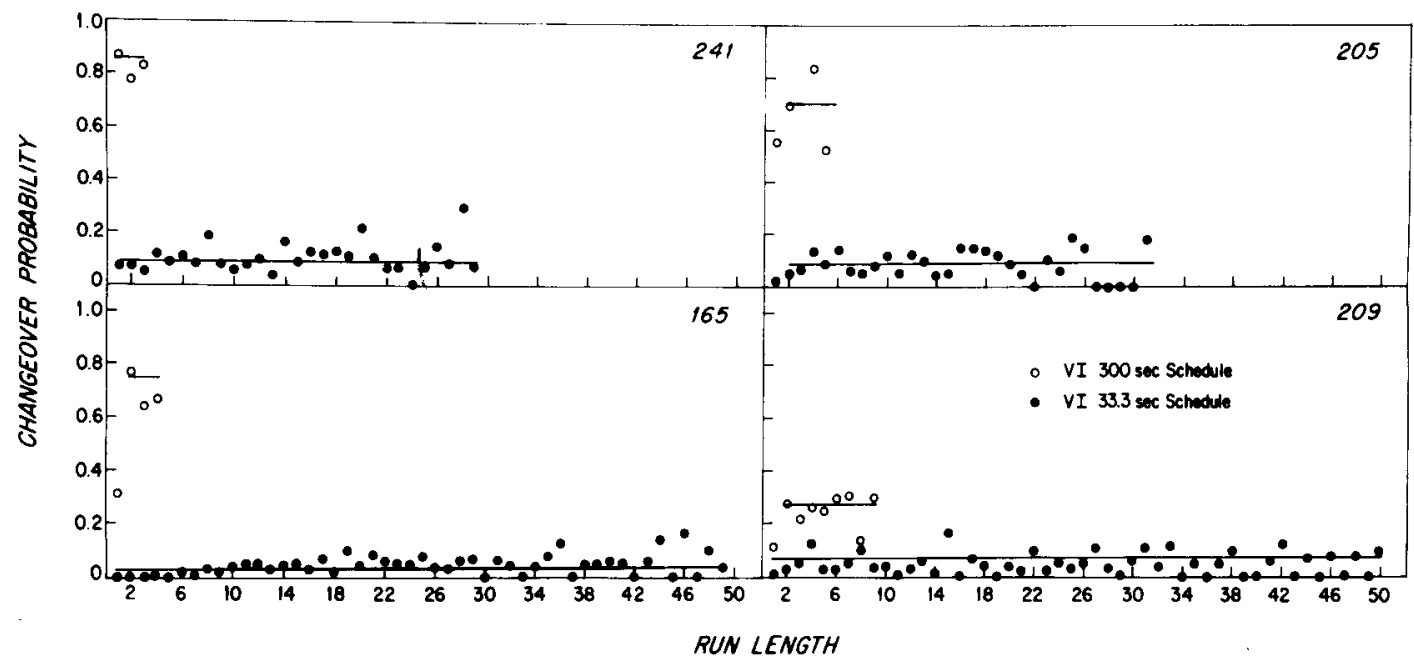

Figure 1. The probability of a changeover as a function of the number of responses since the last changeover (run length). The data are from four different pigeons from the last session the VI 33.3-sec VI 300-sec schedule was in effect. The solid lines show the locus of points which define stationarity. According to a chi-square test, the obtained data did not differ significantly from the stationary value (Heyman, 1979). When the solid line starts at the first postchangeover response, the first postchangeover responses were included in the calculation of the stationary value; when the solid line starts at the second postchangeover response, the calculation of the stationary value did not include first postchangeover responses. (Figure 1 used by permission of the copyright holder, Society for the Experimental Analysis of Behavior, Inc.)

VI $40 \mathrm{sec}$ and VI $120 \mathrm{sec}$ SCHEDULES

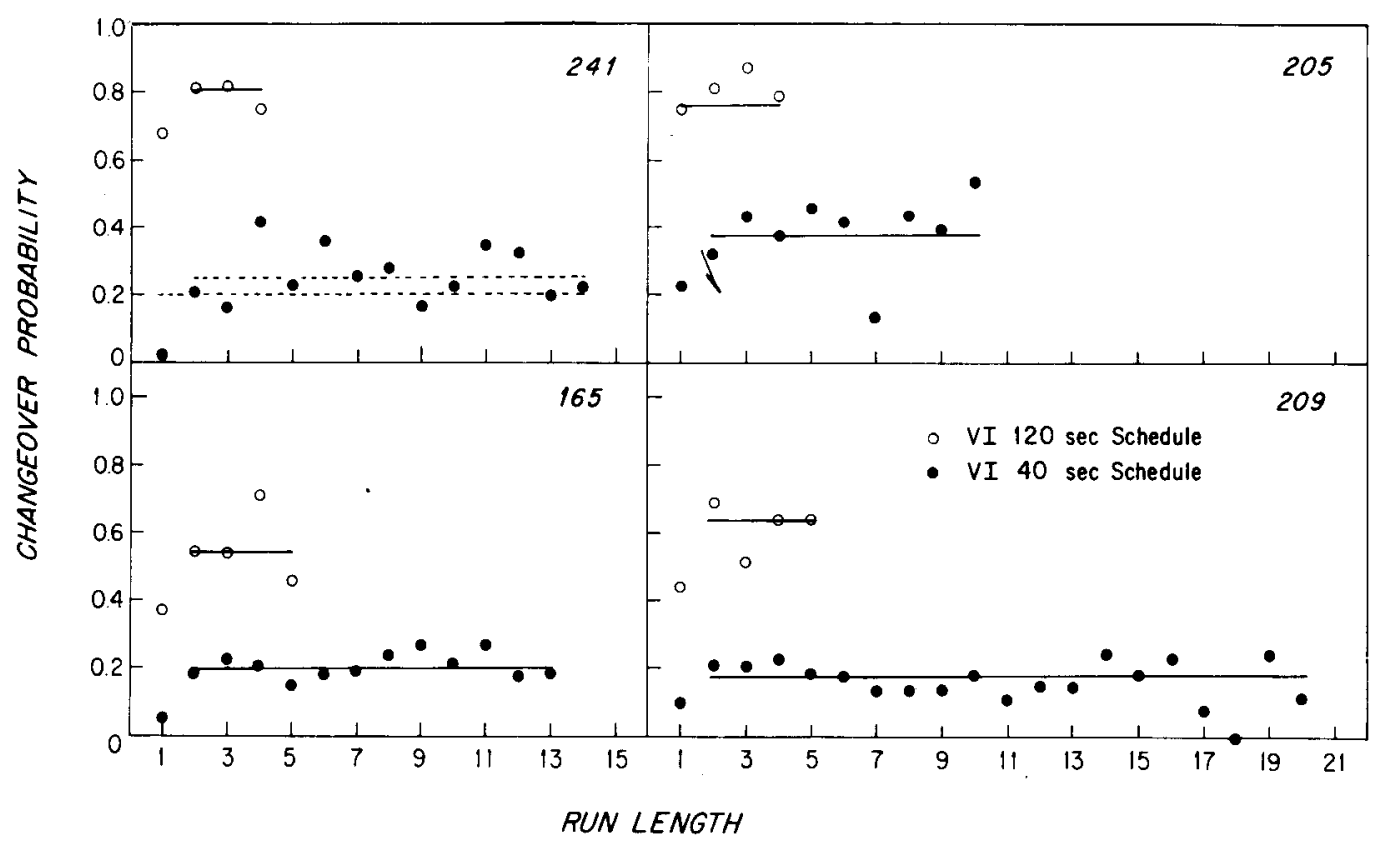

Figure 2. The coordinates and subjects are the same as in Figure 1. The data are from the last session the VI 40-sec VI 120-sec schedule was in effect. The solid lines give the predicted stationary values and indicate that the changeover probabilities are stationary according to a chi-square test. The broken lines, Pigeon 241 , indicate that the changeover probabilities are not stationary by the chi-square criterion. The obtained $p$ was $<.01$. The two predictions which were tested, but failed, are shown. The broken line which starts at the first postchangeover response is the predicted stationary value when first postchangeover responses were included in the calculation; the broken line which starts at the second postchangeover response is the predicted stationary value when first postchangeover responses are omitted from the calculation. (Figure 2 used by permission of the copyright holder, Society for the Experimental Analysis of Behavior, Inc.) 
horizontal lines defining stationarity. In 21 of 24 tests (16 of which are shown in Figures 1 and 2), there was not a significant difference between the predicted stationary values and the changeover probabilities, $p>.05$. The changeover probabilities which are not stationary fluctuate in a manner which suggests that occasionally the birds responded in twopeck bursts, for example Pigeon 241, Figure 2. Similarly, in a discrete-trial choice procedure in which reinforcers were arranged for pigeons on conc VI VI schedules (Herrnstein, 1971), changeover probabilities appeared stationary (the data are displayed in de Villiers, 1977). Since other data suggest that the rate of responding is relatively constant on VI schedules (Catania \& Reynolds, 1968), the constancy of the plotted functions in Figures 1 and 2 implies approximate constancy as a function of time since the last changeover. In a study of the temporal structure of chicks pecking colored hat pins (Machlis, 1977), the intervals between pecks and bouts of pecking and not pecking were adequately described by exponential distributions, which, with independence of the intervals, defines the process we are assuming. We denote by $\mu_{1}$ and $\mu_{2}$ the two exponential intensity parameters (time constants).

Third, we assume, as is true to a good approximation, that the subject's rate of responding is so high relative to the mean programmed interreinforcement intervals that, when a subject is attending to an alternative, we may neglect the delay between the setup of a reinforcer and its receipt. This assumption is satisfied exactly by procedures in which reinforcement is contingent on continuous activity, such as attending to a key light (Brownstein \& Pliskoff, 1968), and it is approximately correct for procedures requiring a discrete response because VI schedules maintain such high response rates.

Although it is possible to derive the equation for expected reinforcement rate from direct arguments involving only mean delays (Heyman, 1977), it is almost as easy to develop the complete theory of distributions of reinforcements.

Let $p_{j}(k, t)$ denote the joint conditional probability density that the subject is attending to alternative $k$ at time $t$, given that it was attending to alternative $j$ at time 0 . For example, for $p_{1}(1, t)$ the subject may have stayed at side 1 from time 0 to time $t$, which occurs with probability $\mathrm{e}^{-\mu_{1} \mathrm{t}}$, or it first switched to side 2 at some time $x<t$ and then returned to side 1 at least once and is there at time $t$ :

$$
p_{1}(1, t)=e^{-\mu_{1} t}+\int_{0}^{t} \mu_{1} e^{-\mu_{1} x_{1}} p_{2}(1, t-x) d x
$$

For $\mathrm{p}_{2}(1, \mathrm{t})$, the subject must have switched from side 2 to side 1 , the first time at some time $x \leqslant t$ and it continues to be there at time $t$ :

$$
\mathrm{p}_{2}(1, \mathrm{t})=\int_{0}^{\mathrm{t}} \mu_{2} \mathrm{e}^{-\mu_{2} \mathrm{x}} \mathrm{p}_{1}(1, \mathrm{t}-\mathrm{x}) \mathrm{dx}
$$

Equations for $p_{2}(2, t)$ and $p_{1}(2, t)$ are obtained from Equations 1 and 2, respectively, by interchanging the labels 1 and 2 .

Let $\phi_{j}(t)$ denote the probability density of times between reinforcements on alternative $j$. Note that reinforcement may be obtained in two ways at alternative $j$. First, the subject is at alternative $j$ when the reinforcement first sets up at time $t$; second, the reinforcement sets up at time $x<t$ at alternative $j$ but the subject is at the other alternative and it then returns to alternative $\mathrm{j}$ at time $\mathrm{t}$ :

$$
\begin{aligned}
\phi_{1}(\mathrm{t})= & \lambda_{1} \mathrm{e}^{-\lambda_{1} \mathrm{t}} \mathrm{p}_{1}(1, \mathrm{t}) \\
& +\int_{0}^{\mathrm{t}} \lambda_{1} \mathrm{e}^{-\lambda_{1} \mathrm{x}} \mathrm{p}_{1}(2, \mathrm{x}) \mu_{2} \mathrm{e}^{-\mu_{2}(\mathrm{t}-\mathrm{x})} \mathrm{dx} \\
= & \lambda_{1} \mathrm{e}^{-\lambda_{1} \mathrm{t}} \mathrm{p}_{1}(1, \mathrm{t}) \\
& +\mu_{2} \mathrm{e}^{-\mu_{2} \mathrm{t}} \int_{0}^{\mathrm{t}} \lambda_{1} \mathrm{e}^{\left(\mu_{2}-\lambda_{1}\right) \mathrm{x}} \mathrm{p}_{1}(2, \mathrm{x}) \mathrm{dx}
\end{aligned}
$$

where $\lambda_{\mathrm{i}}=1 / \mathrm{V}_{\mathrm{i}}$.

The expected time between reinforcements at alternative 1 may be calculated from Equation 3 using characteristic functions (i.e., Fourier transforms). Define the following transforms:

$$
\begin{gathered}
\Phi_{1}(\mathrm{~s})=\int_{-\infty}^{+\infty} \mathrm{e}^{\mathrm{ist}} \phi_{1}(\mathrm{t}) \mathrm{dt} \\
\mathrm{P}_{\mathrm{j}}(\mathrm{k}, \ell, \mathrm{s})=\int_{-\infty}^{+\infty} \mathrm{e}^{\mathrm{ist}} \lambda_{\ell} \mathrm{e}^{-\lambda_{l} \mathrm{t}} \mathrm{P}_{\mathrm{j}}(\mathrm{k}, \mathrm{t}) \mathrm{dt},
\end{gathered}
$$

where $\mathrm{i}=\sqrt{-1}$. Equation 3 then becomes:

$$
\Phi_{1}(\mathrm{~s})=\mathbf{P}_{1}(1,1, \mathrm{~s})+\frac{\mu_{2}}{\mu_{2}-\text { is }} \mathbf{P}_{1}(2,1, \mathrm{~s}),
$$

and Equations 1 and 2 and their analogues with alternatives 1 and 2 interchanged yield:

$$
\begin{aligned}
& \mathrm{P}_{1}(1,1, \mathrm{~s})=\frac{\lambda_{1}\left(\lambda_{1}-\mu_{2}-\mathrm{is}\right)}{\left(\lambda_{1}+\mu_{1}-\mathrm{is}\right)\left(\lambda_{1}+\mu_{2}-\mathrm{is}\right)-\mu_{1} \mu_{2}}, \\
& \mathrm{P}_{1}(2,1, \mathrm{~s})=\frac{\lambda_{1} \mu_{2}}{\left(\lambda_{1}+\mu_{1}-\mathrm{is}\right)\left(\lambda_{1}+\mu_{2}-\mathrm{is}\right)-\mu_{1} \mu_{2}} .
\end{aligned}
$$

To obtain the expected time between reinforcements, we use the fact that

$$
E\left(T_{1}\right)=\int_{0}^{\infty} t \phi_{1}(t) d t=i \lim _{s \rightarrow 0} \frac{d \Phi_{1}(s)}{d s} .
$$


Substituting, we calculate

$$
\mathrm{E}\left(\mathrm{T}_{1}\right)=1 / \lambda_{1}+\frac{\mu_{1} / \mu_{2}}{\lambda_{1}+\mu_{1}+\mu_{2}}
$$

A similar calculation yields $E\left(T_{2}\right)$, from which we obtain

$E(R)=\frac{p}{V_{1}}+\frac{1-p}{V_{1}+I / p}+\frac{1-p}{V_{2}}+\frac{p}{V_{2}+I /(1-p)}$,

where $\mathrm{p}=\mu_{2} /\left(\mu_{1}+\mu_{2}\right)$ is the proportion of time spent at alternative $1, \mathrm{~V}_{\mathrm{j}}$ is the mean programmed interreinforcement interval at alternative $\mathrm{j}$, and $\mathrm{I}=$ $1 /\left(\mu_{1}+\mu_{2}\right)$ is one-half the harmonic mean of the mean time between switches. (The individual times are $\mathrm{I} / \mathrm{p}=1 / \mu_{2}$ and $\left.\mathrm{I} /(1-\mathrm{p})=1 / \mu_{1}.\right)$

Each of the four terms of Equation 11 have natural interpretations. With probability $p$, the subject is at alternative 1 when that alternative sets up, which happens at a mean rate of $1 / V_{1}$. With probability $1-\mathrm{p}$, the subject is attending to alternative 2 when the setup occurs at alternative 1 , which introduces an additional mean delay of $I / p$ until the subject switches back and receives the reinforcer. These are the two ways that reinforcement can occur at alternative 1 . The other two terms correspond to reinforcements at alternative 2 , and the rates add to give the overall reinforcement rate.

We have replaced $\mu_{1}$ and $\mu_{2}$, which characterize the behavior, with the equivalent parameters $p$ and $I$. This is because $\mathrm{p}$ is the variable usually discussed. For example, the matching law simply states that

$$
\mathrm{p}=\mathrm{V}_{2} /\left(\mathrm{V}_{1}+\mathrm{V}_{2}\right) .
$$

The parameter I is an index of the subject's tendency to stay at an alternative; when $I$ is large, the average visit times are long and changeover rate between the alternatives is low. Moreover, the data (Heyman, 1977) suggest that $\mu_{1}$ and $\mu_{2}$ change reciprocally so that I remains approximately constant with changes in p. For example, if $I$ is constant, then the expected number of changeovers per second is $2 p(1-p) / I$. This means that changeover rate should show a negatively accelerated increase as $p$ goes from exclusive preference to indifference, with the maximum at $1 / 2$. Data from experiments with humans (Baum, 1975), rats (Baum, 1973b), and pigeons (Stubbs \& Pliskoff, 1969) show this relationship.

Figure 3 shows how $E(R)$ varies with $p$ for values of I which include the range observed in experimental studies. The location of the maximum is indicated by the solid triangles. According to Equation 12, matching occurs for this schedule at $3 / 4$. Except for $I=0$, where the maximum is independent of $\mathrm{p}$, matching
EXPECTED REINFORCEMENT RATE

ON A CONCURRENT VI $60 \mathrm{sec}$ VI $180 \mathrm{sec}$ SCHEDULE

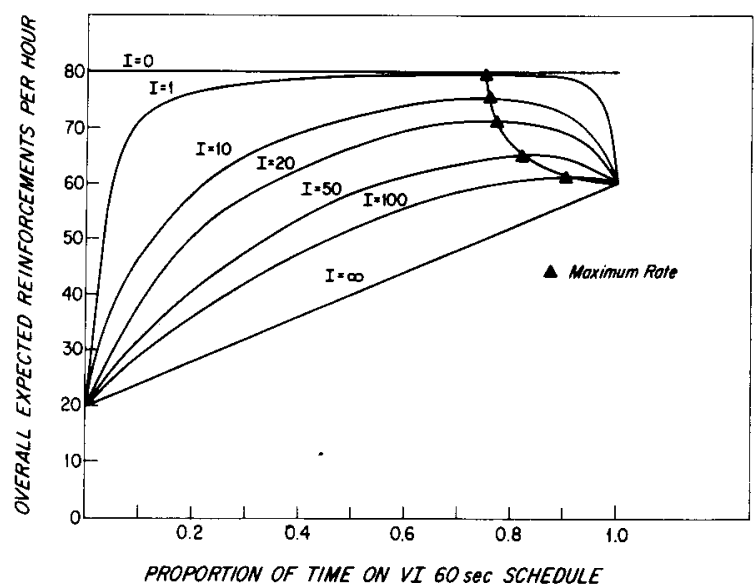

Figure 3. The expected reinforcement rate on a conc VI 60-sec VI 180-sec schedule. The curves were drawn according to Equation 11, and the value of the parameter I (changeover rate) was varied to draw the different curves. This means that the differences between the curves show the effect that changeover rate has on reinforcement rate on a conc VI VI schedule (see text). For example, at $p=.75$ and $I=10 \mathrm{sec}$, the expected reinforcement rate is approximately 75 reinforcements $/ h$, while at the same p value but $I=50 \mathrm{sec}$, it is approximately 65 reinforcements $/ h$. The filled triangles show the locations of the maxima. Matching and maximizing do not agree at any value of $I$, although subjects match on this type of schedule.

and maximizing do not agree for any $I$, and the difference increases with increasing $I$. To get some idea of reasonable values of $I$, note that changeover rates typically vary from about 1 to $30 / \mathrm{min}$. So for $\mathrm{p}=1 / 2$ and $\mathrm{I}=1 \mathrm{sec}$, the changeover rate $[2 p(1-p) / I]$ is $30 / \mathrm{min}$, whereas at the same $p$ but with $I=30 \mathrm{sec}$, the changeover rate is $1 / \mathrm{min}$.

\section{A Model for Interdependent Conc VI VI Performance}

Equation 12 defines the matching value by the programmed relative reinforcement rate. However, experimenters typically calculate the obtained relative reinforcement frequency, which varies somewhat with the subject's distribution of time between the schedules. Because of this interdependency, a procedure is frequently used in which the relative reinforcement frequency is precisely fixed and independent of responding (Stubbs \& Pliskoff, 1969). This is achieved by making the two timers interdependent: when one timer sets up, the other is also stopped so that the assigned reinforcements are collected in order and the programmed proportions are necessarily the obtained proportions.

Following the assumptions and logic that led to Equation 11 (the stationary changeover probabilities in Figures 1 and 2 are from a conc VI VI schedule with linked alternatives), the expected reinforcement rate for an interdependent conc VI VI schedule is: 


$$
\begin{aligned}
E(R)= & \frac{1}{V_{1}}+\frac{1}{V_{2}}-\frac{p I}{V_{2}\left[I+(1-p) V_{2}\right]}-\frac{(1-p) I}{V_{1}\left(I+p V_{1}\right)} \\
& -\frac{p I}{V_{1}\left[I+(1-p) V_{2}\right]}-\frac{(1-p) I}{V_{2}\left(I+p V_{1}\right)}
\end{aligned}
$$

The first two terms show the programmed reinforcement rate, which is also the maximum possible; the third and fourth terms give the expected rate of reinforcement loss at an unattended alternative, which occurs when a reinforcement sets up there; and the fifth and sixth ones give the expected rate of reinforcement loss at the attended schedule-remember that on the interdependent conc VI VI procedure, the attended schedule stops running when a reinforcement has set up at the unattended one. Note also that if the loss rate at the attended schedule is excluded (terms 5 and 6), Equation 13 describes an independent conc VI VI procedure, and it gives the same result as Equation 11.

Figure 4 shows how $E(R)$ varies with $p$ for the interdependent procedure. The abscissa is the same as the obtained reinforcement proportions. Matching and maximizing do not agree for any I, and the maximizing value approaches $1 / 2$ for large I. Importantly, pigeons (Stubbs \& Pliskoff, 1969) and humans (Baum, 1975) match on interdependent conc VI VI schedules (other species have not been tested), and apparently they do so independently of changeover rates and overall reinforcement rates (Fantino, Squires, Delbruck, \& Peterson, 1972). The available data, then, suggest that the large discrepancy between the theoretical maximizing value and the observed performance, matching, in interdependent

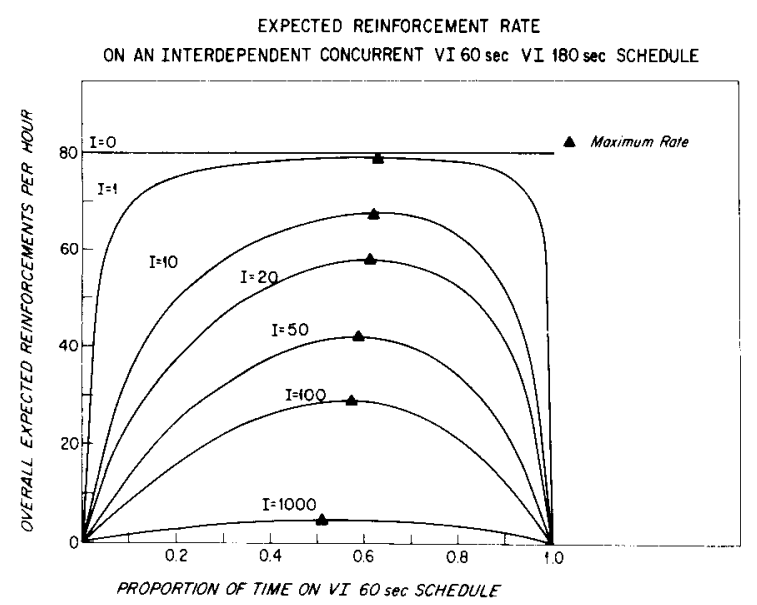

Figure 4. The expected reinforcement rate on an interdependent conc VI 60-sec VI 180-sec schedule. On the interdependent procedure, the experimenter fixes the overall proportion of reinforcements so that the abscissa gives the obtained reinforcement proportions. The parameter, $I$, indexes changeover rate as in Figure 3 (see text), and the triangles show the location of the maxima.
Table 1

A Comparison of the Obtained and Predicted (Equation 13) Reinforcement Rates for Some Interdependent

\begin{tabular}{|c|c|c|c|}
\hline \multirow{2}{*}{$\begin{array}{l}\text { Conc VI VI } \\
\text { Schedules* }\end{array}$} & \multirow[b]{2}{*}{ Subject } & \multicolumn{2}{|c|}{ Reinforcements per Hour } \\
\hline & & Obtained & Predicted \\
\hline $\begin{array}{r}33.3 \\
300\end{array}$ & $\begin{array}{l}165 \\
205 \\
209 \\
241\end{array}$ & $\begin{array}{l}109.53 \\
114.77 \\
114.41 \\
114.89\end{array}$ & $\begin{array}{l}110.35 \\
112.24 \\
111.92 \\
113.37\end{array}$ \\
\hline $\begin{array}{r}40 \\
120\end{array}$ & $\begin{array}{l}165 \\
205 \\
209 \\
241\end{array}$ & $\begin{array}{r}95.96 \\
115.08 \\
111.57 \\
115.63\end{array}$ & $\begin{array}{l}107.23 \\
113.39 \\
113.26 \\
114.37\end{array}$ \\
\hline $\begin{array}{l}60 \\
60\end{array}$ & $\begin{array}{l}165 \\
205 \\
209 \\
241\end{array}$ & $\begin{array}{l}106.25 \\
114.77 \\
113.62 \\
113.33\end{array}$ & $\begin{array}{l}106.25 \\
114.96 \\
113.51 \\
114.12\end{array}$ \\
\hline
\end{tabular}
Conc VI VI Schedules

Note-The data are from the last session each schedule was in effect. The subjects showed close matching in each condition, and a changeover delay contingency was not used (Heyman, 1979). $\quad$ *In seconds.

conc VI VI schedules is independent of species, $\mathrm{V}_{\mathrm{i}}$, and $\mathrm{I}$.

Table 1 compares the predicted reinforcement rates from Equation 13 with the rate obtained in a study with pigeons (Heyman, 1979). The programmed VI values summed to 120 reinforcements/h, there was a discrete response requirement, a keypeck, the changeover delay was omitted (Findley, 1958), and the pigeons showed matching which was well within the normal range. To account for the response requirement, the respective average interresponse times were added to the denominators of the first two terms of Equation 13. The predictions were then obtained by inserting the programmed values for $V_{i}$ and the obtained performance parameters for $p$ and $I$ into the equation. The average absolute discrepancy was about 2 reinforcements $/ \mathrm{h}$, or $2 \%$. Thus, Equation 13 provides a reasonably precise model of interdependent conc VI VI performance.

\section{Generality of the Exponential Model and its Implications}

Several considerations suggest that the results shown in Figures 3 and 4 apply generally to conc VI VI performance.

(1) Although future research is likely to show some individual and procedural variation in switching patterns (Heyman, 1979), the exponential assumption for changeover times is in accord with the presently available data. As cited above, changeover probabilities were approximately stationary for pigeons on independent (Herrnstein, 1971) and interdependent (Heyman, 1979) conc VI VI schedules, and the distribution of intervals between choices for chicks (Machlis, 1977) was approximately exponential. In 
addition, Nevin (1969) recorded changeover probabilities in a discrete-trial version of a conc VI VI schedule. However, Nevin pooled sessions in which the overall average changeover probabilities varied (Nevin, Note 1), so that the results are based on heterogeneous distributions of interchangeover times, and are, therefore, ambiguous (Heyman, 1977). The exponential model, then, appears to describe switching for pigeons in concurrent schedules, and data discussed elsewhere (Heyman, 1979) suggest that this model may also be approximately correct for other species as well.

(2) It can also be shown that matching and maximizing are also different when changeover probabilities are not stationary. An expected reinforcement rate equation was derived for the situation in which the subject switches from schedule $i$ at precisely time $\mathrm{t}_{\mathrm{i}}$ (Heyman, 1977). That is, according to this model, the probability of a changeover is 0 at time $t$ less than $t_{i}$ and 1 at time $t_{i}$, so that for each value of $p$ there are just two interchangeover times, $I /(1-p)$ at schedule 1 and $\mathrm{I} / \mathrm{p}$ at schedule 2 . In contrast, for the exponential model there was an exponential distribution of times at each schedule for each value of $p$. Nevertheless, the reinforcement rate equation for the fixed-time switching process showed about the same magnitude of difference between matching and maximizing and about the same absolute reinforcement rates as did the equation based on the Poisson switching process (Equation 11). That two very different models of switching, the exponential and fixed time, predict similar outcomes suggests that there is a wide range of other switching patterns for which matching and maximizing are different.

(3) The maximizing hypothesis described by Rachlin et al. (1976) depends on the assumption that the distribution of time in a concurrent schedule is controlled by the overall reinforcement rate. Figures 3 and 4 imply that this assumption is generally incorrect. The reinforcement contingencies in independent and interdependent conc VI VI schedules are different. Accordingly, as Figures 3 and 4 show, the maximizing solutions for each are different. Yet it is well established (de Villiers, 1977) that subjects match in both procedures, and there is some evidence that the switching patterns in the two procedures are also approximately the same (Herrnstein, 1971; Heyman, 1979). Similarly, elsewhere (Herrnstein \& Heyman, in press) one of us showed that in a concurrent schedule in which reinforcers were arranged by a variable-interval schedule at one alternative and a variable-ratio schedule at the other (conc VI VR), pigeons matched even though maximizing overall reinforcement rate predicted a much different overall distribution of behavior. Maximizing reinforcement rate, then, predicts different outcomes for conc VI VR and independent and interdependent conc VI VI schedules, yet in each of the procedures, subjects match to about the same degree of error. This result is only possible if the distribution of times between the competing reinforcement sources was not controlled by the overall reinforcement rate.

To summarize the results so far, then, matching and maximizing are different for an exponential switching process in independent and interdependent conc VI VI schedules; other evidence and arguments suggest that this difference is not specific to the Poisson model of behavior; and an analysis very similar to that presented above shows that matching and maximizing are also quite different in a conc VI VR procedure (Herrnstein \& Heyman, in press).

\section{Factors Not Considered by the Models}

Although both independent evidence (Herrnstein, 1971; Heyman, 1979; Machlis, 1977) and the good fit of Equation 13 to some data (Table 1) indicate that our assumptions and logic approximate experimental situations, we need to consider explicitly some possible complicating factors.

(1) Conc VI VI schedules often include the contingency that changeover responses initiate a brief interval during which reinforcements are not delivered. This is called a changeover delay (Findley, 1958), and it has been said that the matching result depends on its inclusion (Mackintosh, 1974; Shimp, 1975). However, it is possible to obtain quite acceptable matching without the delay contingency in both independent (Baum, 1974; Bradshaw, Szabadi, \& Bevan, 1976; Findley, 1958) and interdependent (Heyman, 1979; Stubbs \& Pliskoff, 1969) procedures. Moreover, the changeover delay has little effect on overall reinforcement rate when the delay interval is short, say $1.5 \mathrm{sec}$, so that models of concurrent performance which do not represent the changeover contingency may nevertheless accurately predict the obtained reinforcement rate (Herrnstein \& Heyman, in press). Therefore, the effects of the changeover delay need not be modeled to establish the argument that maximizing overall reinforcement rate is not a sufficient condition for matching.

(2) We did not include terms for response costs or effort. However, the evidence shows that response effort must be virtually independent of the overall distribution of time in conc VI VI performance. First, the overall rate of responding remains approximately constant with changes in $p$ (Catania, 1966). Second, overall response rates vary slightly (Catania, 1966; McSweeney, 1977) or not at all (Fantino et al., 1972 ) with overall reinforcement rate. Therefore, if response rates in conc VI VI procedures do not vary, response costs must have little, if any, relevance to the issue of whether matching depends on maximizing overall reinforcement rate.

(3) Nonscheduled reinforcements take up some 
fraction of the subject's time during an experimental session. For example, for pigeons such activities as preening, wing flapping, and inspecting the houselights interrupt responding at the arranged reinforcement sources. However, cumulative recorder tracings and the good fit of Equation 13 suggest that this fraction is quite small, so that it is unlikely that including terms for extraneous reinforcements in the models would alter the account given here.

(4) In contrast to our findings, Rachlin et al. (1976) claim that maximizing overall reinforcement rate explains matching. Their conclusion is based on a computer simulation of an independent conc VI VI schedule. They found that under certain conditionsthe study was not exhaustive, nor the results consistent-that maximizing closely approximated matching. For example, according to the simulation, matching and maximizing differed by $2 \%$ with a 2 -sec changeover delay and differed by $8 \%$ with a 0 -sec delay, that is, no delay contingency. However, Rachlin et al. (1976) assumed that changeover rate was independent of $p$ and fixed at $6 / \mathrm{min}$. This is not in accord with the data; changeover rate varies with $p$, and the form this relationship takes is often approximated by the exponential process prediction, 2p(1-p)/I (see, e.g., Herrnstein, 1961; Stubbs \& Pliskoff, 1969).

(5) Also in contrast to our results, Shimp (1969) has argued that maximizing leads to matching. His hypothesis is based on the assumption that subjects respond to the schedule with the highest probability of reinforcement at the moment. However, Figures 1 and 2 and other data (Herrnstein, 1971; Nevin, 1969) show that matching occurs when subjects do not follow the response strategies predicted by the momentary maximizing hypothesis.

\section{Conclusion}

Figures 1 and 2 and other data showed that matching may occur in independent and interdependent conc VI VI procedures when the probability of switching from one alternative to the other is approximately stationary. Figures 3 and 4 showed that when changeover probabilities are approximately stationary in conc VI VI procedures, maximizing is different from the observed behavior, matching. In addition, other data and arguments suggested that matching does not follow from maximizing for a number of other switching patterns, and it was pointed out that Figures 3 and 4 imply that the distribution of time in a conc VI VI schedule is not controlled by the overall reinforcement rate, as assumed by the maximizing hypothesis. At the very least, then, we have shown that maximizing overall reinforcement rate is not a sufficient condition for matching. In contrast, those who have argued for maximizing have yet to demonstrate a plausible model of behavior which supports their hypothesis.

\section{REFERENCE NOTE}

1. Nevin, J. A. Personal communication, 1978.

\section{REFERENCES}

BaUm, W. M. The correlational-based law of effect. Journal of the Experimental Analysis of Behavior, 1973, 20, 137-153. (a)

BAUM, W. M. Time allocation and negative reinforcement. Journal of the Experimental Analysis of Behavior, 1973, 20, 313-322. (b)

Balm, W. M. Choice in free ranging wild pigeons. Science, $1974,185,78-79$

BAUM, W. M. Time allocation and human vigilance. Journal of the Experimental Analysis of Behavior, 1975, 23, 45-53.

Bradshaw, C. M., Szabadi, E., \& Bevan, P. Behavior of humans in variable-interval schedules of reinforcement. Journal of the Experimental Analysis of Behavior, 1976, 26, 135-141.

Brownstein, A. J., \& Pliskoff, S. S. Some effects of relative reinforcement rate and changeover delay in responseindependent concurrent schedules of reinforcement. Journal of the Experimental Analysis of Behavior, 1968, 11, 683-688.

Catania, A. C. Concurrent operants. In W. K. Honig (Ed.), Operant behavior: Areas of research and application. New York: Appleton-Century-Crofts, 1966.

Catania, A. C., \& Reynolds, G. S. A quantitative analysis of the responding maintained by interval schedules of reinforcement. Journal of the Experimental Analysis of Behavior, 1968, 11, 327-383.

DE VILLIE RS, P. A. Choice in concurrent schedules and quantitative formulations of the law of effect. In W. K. Honig \& J. Staddon (Eds.), Handbook of operant behavior. Englewood Cliffs, N.J: Prentice-Hall, 1977.

Fantino, E., Squires, N., Delbruck, N., \& Peterson, C. Choice behavior and the accessibility of the reinforcer. Journal of the Experimental Analysis of Behavior, 1972, 18, 35-43.

FindLEY, J. D. Preference and switching under concurrent scheduling. Journal of the Experimental Analysis of Behavior, 1958, 1, 123-144

Fleshler, M., \& Hoffman, H. S. A progression for generating variable interval schedules. Journal of the Experimental Analysis of Behavior, 1962, 5, 529-530.

HerRnSte in, R. J. Relative and absolute strength of response as a function of frequency of reinforcement. Journal of the Experimental Analysis of Behavior, 1961, 4, 267-272.

Herrnstein, R. J. On the law of effect. Journal of the Experimental Analysis of Behavior, 1970, 13, 243-266.

Herrnstein, R. J. Quantitative hedonism. Journal of Psychiatric Research, 1971, 8, 399-412.

Herrnstein, R. J., \& Heyman, G. M. Is matching compatible with reinforcement rate maximization on concurrent VI VR? Journal of the Experimental Analysis of Behavior, in press.

Heyman, G. M. Matching and maximizing. Unpublished doctoral dissertation, Harvard University, 1977.

Heyman, G. M. A Markov model description of changeover probabilities on concurrent variable-interval schedules. Journal of the Experimental Analysis of Behavior, 1979, in press.

MACHLIS, L. An analysis of the temporal patterning of pecking in chicks. Behavior, 1977, 63, 1-70.

Mackintosh, N. J. The psychology of animal learning. New York: Academic Press, 1974.

MCSWEENEY, F. K. Sum of responding as a function of reinforcement on two-key concurrent schedules. Animal Learning \& Behavior, 1977, 5, 110-114.

NEVIN, J. A. Interval reinforcement of choice behavior in discrete trials. Journal of the Experimental Analysis of Behavior, 1969, 12, 875-885.

Rachlin, H., Green, L., Kagel, J., \& Batallio, R. Economic demand theory and psychological studies of choice. The psy. chology of learning and motivation, 1976, 10, 129-154. 
RAPport, D. J., \& TurneR, J. E. Economic models in ecology. Science, 1977, 195, 367-373.

Shimp, C. P. Optimal behavior in free-operant experiments. Psychological Review, 1969, 76, 97-112.

Shimp, C. P. Perspectives on behavioral unit: Choice behavior in animals. In W. K. Estes (Ed.), Handbook of learning and cognitive processes (Vol. 2). Hillsdale, N.J: Erlbaum, 1975.
Stubbs, D. A., \& Pliskoff, S. S. Concurrent responding with fixed relative rate of reinforcement. Journal of the Experimental Analysis of Behavior, 1969, 12, 887-895.

(Received for publication December 15, 1977; revision accepted October 26, 1978.) 